\title{
Acute peripheral facial palsy during chickenpox in a child
}

\author{
Ender Ödemiş ${ }^{1}$, Sadi Türkay ${ }^{1}$, Ayşe Tunca ${ }^{2}$, Ahmet Karadağ ${ }^{1}$ \\ Departments of ${ }^{1}$ Pediatrics and ${ }^{2}$ Neurology, \\ Fatih University Faculty of Medicine, Ankara, Turkey
}

\begin{abstract}
Chickenpox is generally a benign and self-limited infection. However it may occasionally lead to severe complications including meningoencephalitis, purpura fulminans, and hepatitis (1). Several infectious agents including Varicella-zoster virus (VZV), Herpes simplex virus (HSV), Borellia burgdorferi, and Human immonudeficiency virus (HIV) have been reported as the cause of acute peripheric facial palsy (APFP) (2-4). Bell's palsy is primarily an acute paralysis of facial nerve that cannot be attributed to central or peripheral lesions, systemic infections or inflammatory conditions (2). We hereby report a case of acute peripheric facial palsy following chickenpox and discuss the association of VZV with APFP in children.
\end{abstract}

A 4-year-old girl was admitted with drooping of the right corner of the mouth and inability to close her right eye. Her personal and family history were unremarkable. Her vital signs were stable and her weight and height were within normal ranges. She had a history of chickenpox one week earlier. We also observed papulovesicular rash suggesting chickenpox on her trunk. On neurological examination, she had normal facial symmetry at rest, normal movement of the forehead and retained the ability to close eye with minimal effort but with a slight asymmetry. She had no varicella lesions on her ipsilateral ear, otitis media, mastoiditis and no evidence of ear trauma. Her blood pressure was normal. In serum, VZV IgM was positive, but $\mathrm{IgG}$ was negative. She was therefore diagnosed with grade II APFP on the right side according to House Brackmann classification (5). No therapy was started. Ten days later, she could close her eye

Correspondence: Ender Ödemiş, M.D.,

Bağış Sokak. Aytaç Apt. 17/5,

Küçükesat, Ankara/Turkey.

Tel: 009031242594 40, fax: 00903122213670 .

E-mail: biarender@yahoo.com

Received: June 14, 2004.

Revised: August 05, 2004.

Accepted: August 11, 2004. with maximal effort but there was still an obvious asymmetry. She also could move the corners of her mouth with maximal effort but with obvious asymmetry. We considered that the degree of APFP had progressed to grade III at that stage and we started prednisolone $(2 \mathrm{mg} / \mathrm{kg} /$ day per orally once a day) and acyclovir (10 mg/kg/dose per orally every 6 hours). Eight days later, there was a marked recovery in her facial motor nerve functions suggesting improvement towards grade II. Complete recovery was observed on 14th day of the treatment.

Not uncommonly, APFP is misdiagnosed with Bell's palsy. However the term of "Bell's palsy" refers to idiopathic facial palsy. Many infectious agents viral, bacterial and some collagen disorders have been reported in the differential diagnosis of the APFP (2). VZV is the most clearly defined viral cause of the APFP. Ramsay Hunt syndrome is a VZV associated neurological disease characterized by zoster around the ears or in the oropharyx and by APFP (6). Zoster sine herpete (ZSH) is another VZV associated APFP with absence of classical skin eruption of VZV infections confirmed by the detection of VZV by polymerase chain reaction or serological assays $(6,7)$. Reactivation of a prior VZV infection may explain the pathogenesis of the $\mathrm{ZSH}$ (7).

Association of chickenpox and APFP has previously been reported $(3,4)$. Neuropathogenesis of facial palsy caused by VZV infection is unclear. One of explanation is that during chickenpox infection the VZV ascends the sensory ganglia, usually the dorsal root ganglia $(8,9)$. The facial nerve has two sensory branches: pinna for general sensation and tongue for taste sensation. The cell bodies for both these sensory branches are located within the geniculate ganglion in the petrous temporal bone. Chickenpox viruses within vesicles on either the pinna or the tongue may enter the sensory branches of the facial nerve and travel to the geniculate ganglion, where they establish latency $(4,9)$. On reactivation, VZV travels back along the sensory branches of the facial nerve. At the same time, by a bystander effect, the adjacent 
motor branches of the facial nerve become inflamed, leading to facial palsy $(4,9)$. The period between the appearance of the vesicles of the chickenpox and APFP ranges from 5 days before to 16 days after the eruption develops (4). The route of infection is neurogenous in the patients who had palsy after the appearance of the eruptions but is hematogenous in patients who develop the palsy before the appearance of vesicles (4). We therefore think that in our case, the neurogenous route is more likely.

Treatment is still controversial in patients with APFP. High spontaneous recovery rates have been reported $(2,10)$. Three therapies have been proposed: steroids, acyclovir and surgery. Early treatment with oral steroids has probably a beneficial effect on the facial functional outcome. Early treatment with acyclovir and prednisone has also been advocated. There is insufficient evidence to make recommendations regarding the use of surgical facial nerve decompression (11). We started a combination of acyclovir and corticosteroid in our patient in view of the recent history and serological findings of chickenpox, and the progression of the facial nerve motor dysfunction over 10 days without treatment. When acyclovir and corticosteroids are used in combination, patients have been shown to have higher rate of volitional muscle motion and nerve function preservation than those receiving steroids alone $(8,12)$. Because the clinical outcome of VZV related APFP cases is poorer than other cases of Bell's palsy oral acyclovir $(80 \mathrm{mg} / \mathrm{kg} /$ day $)$ is recommended if VZV related facial palsy is a likely etiology $(8,9)$. The clinical improvement we observed 7 days after treatment seems to support the efficacy of the combination therapy.

In conclusion, although this paper is a case report we would like to emphasise that VZV infections should be kept in mind in all cases of APFP in children. This may lead to a decrease in the number of genuinely idiopathic APFP. In view of the poorer prognosis of VZV related APFP than in the genuine Bell's palsy, we believe that a combination therapy with acyclovir and corticosteroids should be considered in such children.

\section{References}

1. Kalyoncu M, Ödemis E, Aynacı M, Karacal UN, Ökten A. An unusual varicella zoster infection complicated by purpura fulminans and multiorgan failure in a healthy infant. Scand J Infect Dis 2003; 35: 74-76.

2. Gilbert SC. Bell's palsy and Herpesviruses. Herpes 2002; 9: 70-73.

3. Deda G, Çaksen H, İçağasığlu D, İnce E. A case of chickenpox associated with facial nerve palsy. Pediatr Dermatol 2002; 19: 95-96.

4. Watanabe Y, Ikeda M, Kukimoto N, Kuga M, Tomita H. A case report of facial nerve palsy associated with chickenpox. J Laryngol Otol 1994; 108: 676-678.

5. Croxson G, May M, Mester SJ. Grading facial nerve function: House-Brackmann versus Burres-Fisch methods. Am J Otol 1990; 11: 240-246.

6. FurutaY, Fukuda S, Suzuki S, Takasu T, Inuyama Y, Nagashima K. Detection of varicella-zoster virus DNA in patients with acute peripheral facial palsy by polymerase chain reaction and its use for early diagnosis of zoster sine herpete. J Med Virol 1997; 52: 316-319.

7. Mori T, Nagai K, Asanuma H. Reactivation of varicella-zoster virus in facial palsy associated with infectious mononucleosis. Pediatr Infect Dis J 2002; 21: 709-711.

8. Grose C, Wiedeman J. Generic acyclovir versus famciclovir and valacyclovir. Pediatr Infect Dis J 1997; 16: 838-841.

9. Grose C, Bonthius D, Afifi AK. Chickenpox and the geniculate ganglion: facial nerve palsy, Ramsay Hunt syndrome and acyclovir treatment. Pediatr Infect Dis J 2002; 21: 615-617.

10. Peitersen E. Bell's palsy: the spontaneous course of 2,500 peripheral facial nerve palsies of different etiologies. Acta Otolaryngol Suppl 2002; 549: 4-30.

11. Grogan PM, Gronseth GS. Practice parameter: Steroids, acyclovir, and surgery for Bell's palsy (an evidence-based review): report of the Quality Standards Subcommittee of the American Academy of Neurology. Neurology 2001; 10: 830-836.

12. Adour KK, Ruboyianes JM, Von Doersten PG, et al. Bell's palsy treatment with acyclovir and prednisone compared with prednisone alone: a double-blind, randomized, controlled trial. Ann Otol Rhinol Laryngol 1996; 105: 371-378. 